between $£ 94000$ and $£ 198000$, being more for men than women, and more for workers sensitised to latex or glutaraldehyde than flour or grain. These estimates were extrapolated to the estimated 631 new workers with occupational asthma in 2003, giving lifetime costs for the 2003 cohort of $£ 71.7$ to $£ 100.1$ million. These figures are clearly estimates and may be some way from the true costs; however, the most interesting conclusion was the distribution of the costs between worker, employer and government, with the employer bearing only $3-4 \%$ of the total cost and the remainder being borne fairly equally between worker and government. Occupational asthma is clearly a bad disease for the worker and the government, the employer having little financial incentive to control the cause.

There are two main approaches to reduce the impact and costs of occupational asthma, either reducing the incidence or limiting its consequences. Occupational asthma is a preventable disease. Glutaraldehyde asthma in the UK has vanished at little extra cost, initially following limitation of glutaraldehyde use and then its replacement for cold sterilisation. The replacement of latex with nitrile and other materials for gloves was delayed while the costs of replacements decreased, latex asthma now being uncommon in UK medical practice. ${ }^{7}$ Both these examples have taken many years from the identification of the problem to its control. Flour in bakers and isocyanates in moulders and painters have been more difficult to control; both still remain common causes of occupational asthma.

The medical consequences of occupational asthma are reduced by early removal from exposure, which can be enhanced by medical surveillance detecting early disease. $^{2}$ In the UK, occupational health is not part of the National Health Service, is not compulsory and when provided is managed by individual contracts between employer and provider. Many of these do not include management of surveillance failures $^{8}$ contributing to the delay in diagnosis even when surveillance is in place. ${ }^{9}$ Reducing the impact of occupational asthma, and therefore reducing the lifetime costs, requires the return of the worker to employment without loss of productivity or income for the worker. For those who wish to work again, proper assessment of the workers' abilities and preservation of income while retraining is surely the way forward. This requires a change in many compensations schemes away from providing a regular pension for many years to compensation focused on support during retraining and return to work.

Competing interests None.
Provenance and peer review Commissioned; not externally peer reviewed.

Published Online First 20 November 2010

Thorax 2011;66:92-93. doi:10.1136/thx.2010.151506

\section{REFERENCES}

1. Anees W, Moore VC, Burge PS. FEV 1 decline in occupational asthma. Thorax 2006;61: 751-5.

2. Nicholson PJ, Cullinan P, Burge PS, et al. Occupational asthma: prevention, identification and management. Systematic review and recommendations. London: British Occupational Health Foundation, 2010.

3. Dewitte JD, ChanYeung M, Malo JL. Medicolegal and compensation aspects of occupational asthma. Eur Respir J 1994;7:969-80.

4. Gannon PFG, Burge PS. The SHIELD scheme in the West Midlands Region, United Kingdom. Br J Ind Med 1993;50:791-6.

5. Ayres JG, Boyd R, Hurley JF. The costs of occupational asthma in the UK. Thorax 2011;66:128-33.

6. Ross DJ. Ten years of the SWORD project. Surveillance of work-related and occupational respiratory disease. Clin Exp Allergy 1999;29: 750-3

7. Bakerly ND, Moore VC, Vellore AD, et al. Fifteen-year trends in occupational asthma: data from the Shield surveillance scheme. Occup Med (London) 2008;58:169-74

8. Mackie J. Effective health surveillance for occupational asthma in motor vehicle repair. Occup Med (London) 2008; 58:551-5.

9. Fishwick D, Bradshaw L, Davies J, et al. Are we failing workers with symptoms suggestive of occupational asthma? Primary Care Respir J 2007;16 304-10.

\title{
What's nice about the new NICE guideline?
}

\section{John O'Reilly, ${ }^{1}$ Michael Rudolf ${ }^{2}$}

A new national guideline for the management of chronic obstructive pulmonary disease (COPD) was published by the National Institute for Health and Clinical Excellence (NICE) in June. ${ }^{1}$ Although technically only applicable to England and Wales (and even then only if adopted by the Welsh Assembly), it will be perceived by many international authorities as 'the British guideline' (with apologies to our

\footnotetext{
${ }^{1}$ Department of Thoracic Medicine, Aintree University Hospital, Liverpool, UK; ${ }^{2}$ Department of Respiratory Medicine, Ealing Hospital NHS Trust, London, UK

Correspondence to John O'Reilly, Consultant Physician, Department of Thoracic Medicine, Aintree University Hospital NHS Trust, Lower Lane, Liverpool L9 7AL, UK; john.oreilly@aintree.nhs.uk
}

Scottish colleagues), and it therefore seems appropriate to comment on what's new and relevant. It is over 6 years since the last NICE COPD guideline was published, ${ }^{2}$ and it is important to note that this 2010 version is only a partial update, concentrating on various aspects of diagnosis and severity classification and the management of stable disease. The management of acute exacerbations was specifically excluded from the scope of the guideline revision. This has had the consequence of producing a lengthy document (the full web-based version is over 600 pages!), much of which will be regarded by many readers as out of date. The Guideline Development Group (GDG) and the publishers have gone to great lengths to make as obvious as possible which parts of the guideline are new and which are not, but many will feel that this was a lost opportunity in not revising other sections as well.

One of the major strengths of a NICE guideline is that its recommendations are based on systematic reviews of the best available evidence (using extremely strict criteria for assessing the evidence), and also giving explicit consideration to cost effectiveness. ${ }^{3}$ In addition, the GDG is truly multidisciplinary, comprising healthcare professionals (doctors, nurses, physiotherapists) from primary and secondary care and patient representation.

It is good to see that the new NICE guideline now agrees with other international guidelines both in recommending the use of postbronchodilator spirometry for confirmation of diagnosis and also in using the Global Initiative for Chronic Obstructive Lung Disease (GOLD) classification of severity of airflow obstruction (table 1). ${ }^{4} 5$ It was always difficult to rationalise why, for example, a patient with forced expiratory volume in $1 \mathrm{~s}$ 
Table 1 Classification of severity of airflow obstruction

\begin{tabular}{|c|c|c|c|c|c|}
\hline \multirow{2}{*}{$\begin{array}{l}\text { Postbronchodilator } \\
\text { FEV }_{1} / \text { FVC }\end{array}$} & \multirow{2}{*}{$\begin{array}{l}\mathrm{FEV}_{1} \% \\
\text { predicted }\end{array}$} & NICE 2004 & ATS/ERS 2004 & GOLD 2008 & NICE 2010 \\
\hline & & \multicolumn{4}{|c|}{ Severity of airflow obstruction } \\
\hline & & & Postbronchodilator & Postbronchodilator & Postbronchodilator \\
\hline$<0.7$ & $\geq 80$ & & Mild & Stage 1: Mild & Stage 1: Mild* \\
\hline$<0.7$ & $50-79$ & Mild & Moderate & Stage 2: Moderate & Stage 2: Moderate \\
\hline$<0.7$ & $30-49$ & Moderate & Severe & Stage 3: Severe & Stage 3: Severe \\
\hline$<0.7$ & $<30$ & Severe & Very severe & Stage 4: Very severe $†$ & Stage 4: Very severe† \\
\hline
\end{tabular}

${ }^{*}$ Symptoms should be present to diagnose chronic obstructive pulmonary disease in people with mild airflow obstruction. †Or FEV $1<50 \%$ with respiratory failure.

ATS, American Thoracic Society; ERS, European Respiratory Society; FEV , forced expiratory volume in $1 \mathrm{~s}$; FVC, forced vita capacity; GOLD, Global Initiative for Chronic Obstructive Lung Disease; NICE, National Institute for Health and Clinical Excellence.

$\left(\mathrm{FEV}_{1}\right) \quad 30-49 \%$ predicted had 'severe' airflow obstruction (GOLD stage 3) in North America but only 'moderate' (NICE 2004) in the UK. This welcome realignment will lead to some patients having their severity stage reclassified; such patients will need reassurance that their actual clinical condition, their need for appropriate therapy and their prognosis all remain unchanged. It is a shame, but perhaps predictable, that no advice is given as to what actually constitutes a postbronchodilator measurement, but most would agree that a postbronchodilator value is likely to result in greater accuracy in both diagnosis and prevalence assessment. It is also good to note that this supports the recommendation for spirometry in the Department of Health national strategy for COPD. ${ }^{6}$

The new NICE guidance goes beyond other guidelines in requiring that symptoms should be present to diagnose COPD in people with mild airflow obstruction (stage 1), as symptomatic but not asymptomatic GOLD stage 1 COPD has been associated with a faster decline in $\mathrm{FEV}_{1}$, increased respiratory care utilisation and a lower quality of life than in people with normal lung function. ${ }^{7}$

The ongoing controversy about whether a patient's $\mathrm{FEV}_{1}$ /forced vital capacity (FVC) ratio should be regarded as signifying airflow obstruction if it is below a fixed value of $70 \%$, as opposed to being below that individual's calculated lower limit of normal (LLN), is given an airing. ${ }^{8-12}$ While the guideline does not go so far as to recommend LLN owing to a lack of validated reference equations for postbronchodilator spirometry and various ethnic populations, it does specifically point out that sticking with the $70 \%$ cutoff (which is the criterion that it still endorses) may lead to underdiagnosis in younger patients and overdiagnosis in more elderly patients. There is an eminently sensible recommendation to consider alternative diagnoses or further investigations (1) in older people without typical symptoms of COPD where the $\mathrm{FEV}_{1} / \mathrm{FVC}$ ratio is $<0.7$, and (2) in younger people with symptoms of COPD where the $\mathrm{FEV}_{1} / \mathrm{FVC}$ ratio is $\geq 0.7$.

A welcome feature of the guideline, relevant for a number of the recommendations, is the emphasis on the clinical features of COPD and not over-reliance on spirometry. The guideline goes to great lengths to point out that the realigned gradation of spirometry (table 1) refers purely to the severity of airflow obstruction and not the clinical severity of the disease, for which a more comprehensive assessment is necessary. The recommendation above relating to the interpretation of spirometry in younger and older people should highlight the fact that healthcare professionals must use their clinical skills and diagnostic acumen in interpreting spirometry, particularly in their assessment of patients with symptoms and perhaps even more so in evaluating asymptomatic individuals who have been identified as 'abnormal' by screening spirometry. $^{13-15}$ Further education and training for non-specialists who are not spirometry aficionados may well be necessary.

The need for a full multidimensional assessment is made even more apparent in the guideline with the recommendation (more of a statement than a recommendation if one wants to be pedantic) to be aware that disability in COPD can be poorly reflected in the $\mathrm{FEV}_{1}$, and that a more comprehensive assessment of severity should include a number of other factors such as further lung function, breathlessness (MRC scale), health status (although no advice on how to do this) and exercise capacity (eg, a 6 min walk test). The guideline specifically recommends calculating the BODE index where the component data are available, but acknowledges that this may be impractical in a primary care setting. ${ }^{16} 17$ There is clearly an urgent need for a simple and practical multidimensional assessment tool, and the GDG were aware of those in development (eg, the Clinical Assessment Tool (CAT)) but which had not been validated at the time of the guideline update. $^{18}$ This led to an important research recommendation that such tools urgently need to be assessed and validated in a primary care setting.

Bearing in mind the number of important drug studies that have been published since the original 2004 guideline, for many readers the most eagerly awaited part of the new guideline will be the section relating to treatment. ${ }^{19-22}$ There are a number of complex interlocking recommendations for the use of inhaled therapy with short-acting $\beta$ agonists (SABA), short-acting muscarinic antagonists (SAMA), long-acting $\beta$ agonists (LABA), long-acting muscarinic antagonists (LAMA) and LABA plus inhaled corticosteroid (ICS) in a combination inhaler. These are all summarised in a novel clinical algorithm (figure 1) which, depending on your point of view, either provides an excellent succinct flow chart of how to manage COPD in 2010 or proves conclusively that the GDG misinterpreted the evidence! The authors of this editorial, being members of the GDG, clearly believe that this chart provides clarity regarding the clinical and cost-effective use of LABA, LAMA and LABA+ICS. It should be noted that the starting point on the algorithm depends solely on the presence or absence of persistent symptoms (including exacerbations) and whether the $\mathrm{FEV}_{1}$ is above or below $50 \%$ predicted. The strength of the evidence for progressing along the algorithm is indicated by continuous or discontinuous lines. The evidence for, and the reasoning behind, this flow chart (and the individual recommendations on which it is based) is fully documented in the full version of the guideline, but is difficult to follow owing to the methodology that had to be used in addressing individual drug comparisons before building up to sequential treatments and then finally undertaking a health economic assessment. Nevertheless, some key issues do emerge. The use of ICS is recommended only in a combination inhaler with a LABA. The evidence for LABA+ICS was strong in people with severe $\left(\mathrm{FEV}_{1}<50 \%\right)$ or very severe $\left(\mathrm{FEV}_{1}<30 \%\right)$ airflow obstruction and persistent symptoms, but the evidence was weaker (and the recommendation accordingly also weaker as well) in those with only mild or moderate airflow obstruction. The recommendation to consider LABA+LAMA in patients 
Algorithm 2a: Use of inhaled therapies

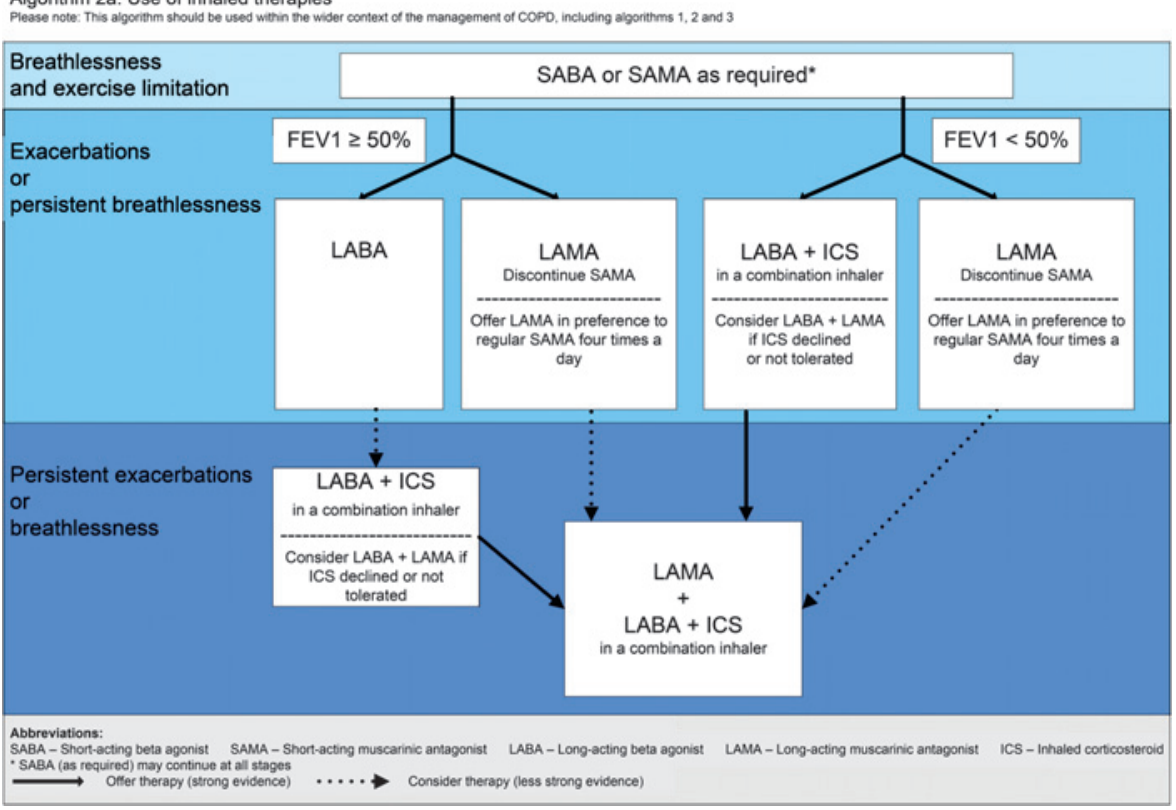

Figure 1 Algorithm showing use of inhaled therapies. FEV ${ }_{1}$, forced expiratory volume in $1 \mathrm{~s}$; ICS, inhaled corticosteroid; LABA, long-acting $\beta$ agonist; LAMA, long-acting muscarinic antagonist; SABA, short-acting $\beta$ agonist; SAMA, short-acting muscarinic antagonist.

unable or unwilling to take ICS was based on a pragmatic approach in the absence of sufficient clinical and health economic evidence.

The recommendation to offer LAMA in addition to LABA+ICS (triple therapy) to those already on LABA+ICS but who remain symptomatic (or continue to have exacerbations), irrespective of their $\mathrm{FEV}_{1}$, was based on strong clinical and health economic evidence. ${ }^{21}$ However, this was not the case for the 'opposite' scenario for the addition of LABA + ICS to those with persistent symptoms on LAMA. Published studies had not been designed or powered to assess this intervention, which is therefore weaker ('consider' rather than 'offer'). ${ }^{22}$ Currently available studies were also not designed or powered to assess whether those with milder disease on single therapy with LABA or LAMA or double therapy with LABA+ICS might benefit from triple therapy. An appropriate research recommendation has been made for this important group, which will comprise increasing numbers of patients once screening programmes identify more people with milder disease.

Although the content of pulmonary rehabilitation courses and their effectiveness were outside the scope of this guideline update, the GDG did review the evidence relating to the benefits of early rehabilitation after an exacerbation. It was noted that the greatest reconditioning and potential benefit from rehabilitation may occur in the early post-exacerbation phase, and the available evidence allowed a recommendation that pulmonary rehabilitation should be made available to all appropriate people with COPD (the appropriateness being fully defined in the guideline) including those who have had a recent hospitalisation for an acute exacerbation (new update in italics). The key role of pulmonary rehabilitation has clearly been identified in the guideline by (1) this recommendation; (2) this also being a key priority for implementation; and (3) a research recommendation for more work in this area. It is good to see a further study, unfortunately not available at the time of the evidence review, supporting this. ${ }^{23}$

So, overall, how nice is NICE? The overall document, which is also (mercifully) published in a shorter compact version as well as a patient-friendly lay version, is a bit of a curate's egg. Unchanged portions from 2004 will not provoke excitement, even though many of these older recommendations (eg, those relating to smoking cessation and the crucial role of multidisciplinary teams) remain just as important and relevant now as they did then. However, for those sections which have been updated, it is good to have available all the evidence, carefully evaluated, for careful examination. Not everyone will agree with all of the recommendations but, in conjunction with the research recommendations and key priorities for implementation, they do provide greater clarity in the diagnosis and management of people with COPD and a worthwhile stimulus to ensure progressive improvement in the standard of care that our patients deserve.

Funding Commissioned by the National Institute of Clinical Excellence.

Competing interests Both authors were members of the Guideline Development Group for the NICE guideline (JO'R the Clinical Advisor and MR the Chair). JO'R has received honoraria for lectures at educational meetings and support for travel and accommodation to attend educational conferences from Boehringer Ingelheim TEVA, GSK, AstraZeneca, Cephalon, UCB and Respironics. MR has received honoraria for lectures at educational meetings and support for travel and accommodation to attend educational conferences from AstraZeneca, GSK, Pfizer, Novartis, MSD, Boehringer Ingelheim and TEVA. Neither author has spouses, partners or children with financial relationships that may be relevant to submitted work, nor non-financial interests that may be relevant to submitted work.

Contributors $\mathrm{JO}$ 'R is Clinical Advisor for the NICE Guideline Development Group. MR is Chair of the NICE Guideline Development Group.

Provenance and peer review Commissioned; not externally peer reviewed.

Published Online First 20 November 2010

Thorax 2011;66:93-96. doi:10.1136/thx.2010.144451

\section{REFERENCES}

1. National Institute for Health and Clinical Excellence. Chronic Obstructive Pulmonary Disease. NICE Guideline (Update) Consultation. London: National Institute for Health and Clinical Excellence, 2010 .

2. National Institute for Health and Clinical Excellence. The Guidelines Manual 2007. London: National Institute for Health and Clinical Excellence, 2007.

3. National Institute for Health and Clinical Excellence. Chronic Obstructive Pulmonary Disease-Management of Chronic Obstructive Pulmonary Disease in Adults in Primary and Secondary Care. (CG12). London: National Institute for Health and Clinical Excellence, 2004.

4. Global Initiative for Chronic Obstructive Lung Disease (GOLD). Global strategy for the diagnosis, management, and prevention of chronic obstructive pulmonary disease, 2008. http://goldcopd.com.

5. Celli BR, MacNee W. Standards for the diagnosis and treatment of patients with COPD: a summary of the ATS/ERS position paper. Eur Respir $J$ 2004;23:932-46.

6. Department of Health. Consultation on a Strategy for Services for COPD in England. London: Department of Health, 2010.

7. Bridevaux PO, Gerbase MW, Probst HN, et al. Long-term decline in lung function, utilisation of care and quality of life in modified GOLD stage 1 COPD. Thorax 2008;63:768-74.

8. Hnizdo E, Glindmeyer HW, Petsonk EL, et al. Case definitions for chronic obstructive pulmonary disease. COPD 2006:3:95-100.

9. Swanney MP, Ruppel G, Enright PL, et al. Using the lower limit of normal for the $\mathrm{FEV}_{1} / \mathrm{FVC}$ ratio reduces the misclassification of airway obstruction. Thorax 2008:63:1046-51

10. Quanjer PH, Tammeling GJ, Cotes JE, et al. Lung volumes and forced ventilatory flows. Report Working Party Standardization of Lung Function Tests, European Community for Steel and Coal. Official 
Statement of the European Respiratory Society. Eur Respir J Suppl 1993;16:5-40.

11. Perez-Padilla R, Hallal PC, Vazquez-Garcia JC, et al. Impact of bronchodilator use on the prevalence of COPD in population-based samples. COPD 2007:4:113-20.

12. Cerveri I, Corsico AG, Accordini S, et al. Underestimation of airflow obstruction among young adults using $\mathrm{FEV}_{1} / \mathrm{FVC}<70 \%$ as a fixed cut-off: a longitudinal evaluation of clinical and functional outcomes. Thorax 2008;63:1040-5.

13. Celli BR, Halbert RJ, Isonaka S, et al. Population impact of different definitions of airway obstruction. Eur Respir J 2003;22:268-73.

14. Hardie JA, Buist AS, Vollmer WM, et al. Risk of over-diagnosis of COPD in asymptomatic elderly never-smokers. Eur Respir J 2002;20:1117-22
15. Shirtcliffe $\mathbf{P}$, Weatherall $\mathrm{M}$, Marsh $\mathrm{S}$, et al. COPD prevalence in a random population survey: a matter of definition. Eur Respir $\mathrm{J}$ 2007; 30:232-9

16. Celli BR, Cote CG, Marin JM, et al. The body-mass index, airflow obstruction, dyspnea, and exercise capacity index in chronic obstructive pulmonary disease. $N$ Engl J Med 2004;350:1005-12.

17. Marin JM, Carrizo SJ, Casanova C, et al. Prediction of risk of COPD exacerbations by the BODE index. Respir Med 2009;103:373-8.

18. Jones PW, Harding G, Berry P, et al. Development and first validation of the COPD assessment test. Eur Respir J 2009:34:648-54.

19. Wedzicha JA, Calverley PM, Seemungal TA, et al. The prevention of chronic obstructive pulmonary disease exacerbations by salmeterol/fluticasone propionate or tiotropium bromide. Am J Respir Crit Care Med 2008;177:19-26.

20. Calverley PM, Anderson JA, Celli B, et al. Salmeterol and fluticasone propionate and survival in chronic obstructive pulmonary disease. N Engl J Med 2007; 356:775-89.

21. Tashkin DP, Celli B, Senn S, et al. A 4-year trial of tiotropium in chronic obstructive pulmonary disease. N Engl J Med 2008;359:1543-54.

22. Aaron S, Vandemheen $\mathrm{K}$, Fergusson D, et al. Tiotropium in combination with placebo, salmeterol, or fluticasone-salmeterol for treatment of chronic obstructive pulmonary disease: a randomized trial. Ann Intern Med 2007;146:545-55.

23. Seymour JM, Moore L, Jolley CJ, et al. Outpatient pulmonary rehabilitation following acute exacerbations of COPD. Thorax 2010;65:423-8 